\title{
The dynamics of pyrethroid resistance in Anopheles arabiensis from Zanzibar and an assessment of the underlying genetic basis
}

Christopher M Jones ${ }^{1}$, Khamis A Haji ${ }^{2}$, Bakari O Khatib ${ }^{2}$, Judit Bagi ${ }^{1}$, Juma Mcha ${ }^{2}$, Gregor J Devine ${ }^{3}$, Matthew Daley ${ }^{1}$, Bilali Kabula ${ }^{4}$, Abdullah S Ali ${ }^{2}$, Silas Majambere ${ }^{1,2,5}$ and Hilary Ranson ${ }^{1^{*}}$

\begin{abstract}
Background: The emergence of pyrethroid resistance in the malaria vector, Anopheles arabiensis, threatens to undermine the considerable gains made towards eliminating malaria on Zanzibar. Previously, resistance was restricted to the island of Pemba while mosquitoes from Unguja, the larger of the two islands of Zanzibar, were susceptible. Here, we characterised the mechanism(s) responsible for resistance on Zanzibar using a combination of gene expression and target-site mutation assays.

Methods: WHO resistance bioassays were conducted using 1-5d old adult Anopheles gambiae s.l. collected between 2011 and 2013 across the archipelago. Synergist assays with the P450 inhibitor piperonyl-butoxide were performed in 2013. Members of the An. gambiae complex were PCR-identified and screened for target-site mutations ( $k d r$ and Ace-1). Gene expression in pyrethroid resistant An. arabiensis from Pemba was analysed using whole-genome microarrays.

Results: Pyrethroid resistance is now present across the entire Zanzibar archipelago. Survival to the pyrethroid lambda-cyhalothrin in bioassays conducted in 2013 was 23.5-54.3\% on Unguja and 32.9-81.7\% on Pemba. We present evidence that resistance is mediated, in part at least, by elevated P450 monoxygenases. Whole-genome microarray scans showed that the most enriched gene terms in resistant An. arabiensis from Pemba were associated with P450 activity and synergist assays with PBO completely restored susceptibility to pyrethroids in both islands. CYP4G16 was the most consistently over-expressed gene in resistant mosquitoes compared with two susceptible strains from Unguja and Dar es Salaam. Expression of this P450 is enriched in the abdomen and it is thought to play a role in hydrocarbon synthesis. Microarray and GPCR detected several additional genes putatively involved in this pathway enriched in the Pemba pyrethroid resistant population and we hypothesise that resistance may be, in part, related to alterations in the structure of the mosquito cuticle. None of the $k d r$ target-site mutations, associated with pyrethroid/DDT resistance in An. gambiae elsewhere in Africa, were found on the islands.
\end{abstract}

Conclusion: The consequences of this resistance phenotype are discussed in relation to future vector control strategies on Zanzibar to support the ongoing malaria elimination efforts on the islands.

Keywords: Anopheles arabiensis, Zanzibar, Pyrethroid resistance, P450s, Gene expression

\footnotetext{
* Correspondence: hranson@liverpool.ac.uk

'Department of Vector Biology, Liverpool School of Tropical Medicine,

Pembroke Place, Liverpool L3 5QA, UK

Full list of author information is available at the end of the article
} 


\section{Background}

A major obstacle facing malaria control is pyrethroid resistance in the malaria vectors, Anopheles gambiae and Anopheles funestus [1,2]. Populations of highly resistant An. gambiae span West Africa [3,4] while pockets of resistance continue to emerge throughout the east of the continent [5-7]. With alternative compounds for long-lasting insecticide nets (LLINs) and indoor residual spraying (IRS) still in the development pipeline, selection for resistance looks certain to continue unabated unless effective resistance management strategies are implemented.

The search for genetic markers underpinning insecticide resistant phenotypes in natural insect populations poses significant challenges. This is exemplified in An. gambiae which displays a profile of resistant phenotypes across Sub-Saharan Africa. Identifying and tracking resistanceassociated genetic markers is identified as a priority in the World Health Organisation's (WHO) Global Plan for Insecticide Resistance Management (GPIRM) [1]. Resistance to pyrethroids and DDT is strongly associated with the knockdown resistance ( $k d r)$ target-site mutations (L1014F/ $S$ ) in the voltage gated sodium channel [8-10] but these mutations cannot account for all the variation observed in resistance bioassays and indeed, are absent from some resistant populations $[11,12]$. Pyrethroid resistance is mediated in part at least by the elevated expression of metabolic gene families (e.g. P450 monooxygenases/glutathione-Stransferases/esterases) and transcriptional profiling of resistant and susceptible An. gambiae followed by functional validation has begun to pinpoint individual genes responsible $[13,14]$.

Substantial reductions in malaria have been made in Zanzibar through (i) the administration of artemisin combination therapies (ACTs), (ii) island wide distribution of LLINs and (iii) IRS campaigns using the pyrethroid, lambda-cyhalothrin $[15,16]$. In 2010, pyrethroid resistance was reported in Anopheles arabiensis from the Zanzibar archipelago [17] but curiously, resistance was confined to the smaller island of Pemba, which lies $50 \mathrm{~km}$ north of the larger island Unguja. It was uncertain whether the discrepancy in resistance levels between Pemba and Unguja was due to different selective forces acting on the islands.

In this study, we set out to characterise the mechanism(s) responsible for the ongoing selection of resistance on Zanzibar using DNA and RNA-based approaches. Furthermore, we continued to monitor for phenotypic resistance across the islands between 2011 and 2013 in view of ongoing strategies for managing the emergence of pyrethroid resistance in Zanzibar.

\section{Methods}

Insect collections

Anopheles larvae were collected from breeding pools across Unguja and Pemba during the main rainy season
(April/May) between 2011 and 2013 (Figure 1). The sites were chosen to represent the typical diversity of breeding grounds present on the islands and their inclusion varied year to year depending on the number of larvae available. Four sites were sampled from Unguja: Mwera, Chuini, Kilimani, and Cheju. Breeding pools from Mwera and Chuini were generally from irrigated rice fields while Cheju is situated within the Jozani forest consisting of varied tropical vegetation. Kilimani is situated on the coastal plain of the major capital Stone Town where the tide frequently submerges breeding sites resulting in brackish water. The breeding sites from Pemba were located in Pujini, Kiungoni, Uwandani, Mangwena and Tumbe. The majority of mosquitoes from these were sampled within rural inland settings with the exception of Tumbe which lies close to the north coast of the island. Mosquitoes were sampled from different pools to reduce sampling bias from families. Larvae were transported to insectaries at ZMCP and reared to adults under $27^{\circ} \mathrm{C} \pm 2^{\circ} \mathrm{C}$.

\section{Phenotypic bioassays}

Resistance assays were performed on one to five day old non blood-fed female adult An. gambiae using WHO susceptibility tests [18]. In 2011 and 2013, An. gambiae were exposed to a selection of the following insecticideimpregnated papers: lambda-cyhalothrin (0.05\%), permethrin (0.75\%), DDT (4\%) and bendiocarb (0.1\%). Insufficient numbers of larvae were collected from some sites to test all insecticides and in these sites we prioritised lambda-cyhalothrin as this insecticide has been sprayed widely across Zanzibar as part of the IRS campaign since 2006 (ZMCP unpublished report, 2011). Control assays using non-treated papers were run alongside all tests. Mortality was scored $24 \mathrm{~h}$ postexposure. In 2013, we performed additional synergism assays with the $\mathrm{P} 450$ inhibitor piperonyl butoxide (PBO). Mosquitoes were pre-exposed to PBO (4\%) for one-hour and then transferred to the insecticide exposure tube for an additional hour. Mortality was scored $24 \mathrm{~h}$ after exposure to insecticide. Control assays exposing mosquitoes to PBO only were run in each synergist assay.

In 2012, a more comprehensive assessment of lambdacyhalothrin resistance was performed to quantify the difference in resistance between An. gambiae from Pemba and Unguja. The lethal concentration for $50 \%$ mortality $\left(\mathrm{LC}_{50}\right)$ was determined from two sites on Unguja (Chuini \& Mwera) and Pemba (Mangwena \& Tumbe). Mosquitoes were exposed to insecticide impregnated papers at a range of five concentrations of lambdacyhalothrin $(0.005 \%-0.2 \%)$ for one hour as described above. 


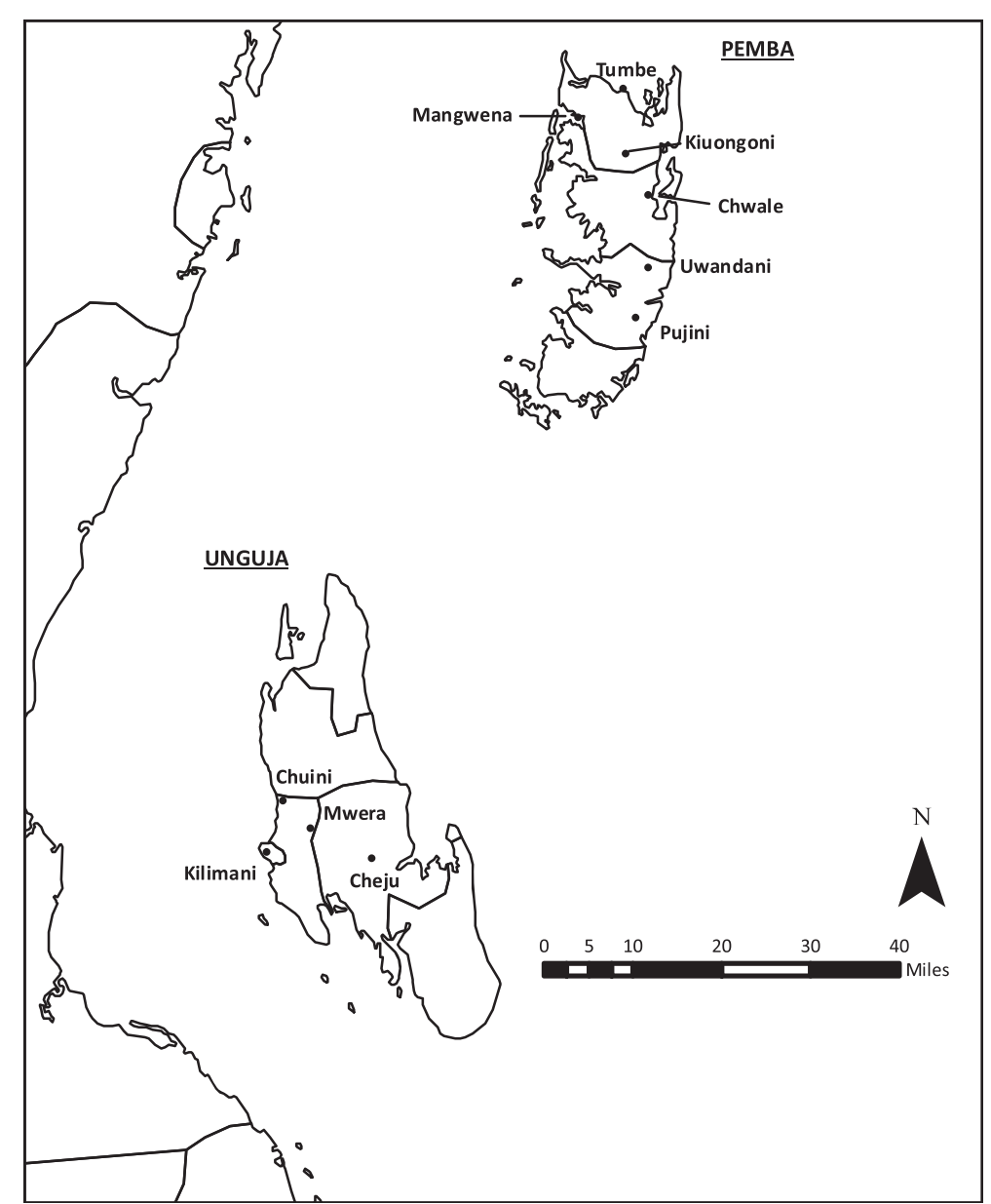

Figure 1 Anopheles larval collection sites from Zanzibar.

\section{An. gambiae complex identification and resistance-associated SNPs}

Members of the An. gambiae species complex were determined using allele specific-PCR [19]. Target-site mutations in the sodium channel (resistance to pyrethroids/DDT) and acetylcholinesterase (ace-1) (resistance to carbamates/ organophosphates) were screened using TaqMan allelic discrimination assays [20,21].

\section{Whole genome microarrays}

To investigate whether differential gene expression underscored the resistant phenotype on Pemba, two whole genome microarray experiments were performed in 2011 and 2012. The emergence of pyrethroid resistance on Pemba, but apparent absence from Unguja, permitted a direct comparison of RNA extracted from mosquitoes from each island. However, in 2011 we were constrained by the number of mosquitoes collected from Unguja and presence of An. gambiae s.s. from our main site Kilimani. Therefore, surviving mosquitoes exposed to lambda-cyhalothrin were compared directly with the insecticide susceptible $A n$. arabiensis lab-colony from Mozambique (MOZ) [11]. In 2012, the experimental design was extended to include mosquitoes from (i) Pemba (Mangwena), (iii) Unguja (Chuini) and (iii) a susceptible field strain of An. arabiensis from Dar es Salaam (DAR). Four day old, non bloodfed $A n$. arabiensis from Ilala and Kinondoni in Dar es Salaam were stored in RNAlater $24 \mathrm{~h}$ post-exposure to insecticide and display no resistance to pyrethroids or DDT. The inclusion of DAR provided an independent susceptible population to improve the strength of resistant gene expression association. Three biological replicates from each strain were integrated into an interwoven loop design as this has been shown to provide robust power in detecting differences in gene expression [22].

The $A n$. gambiae $15 \mathrm{k}$ whole genome microarray was used in all experiments [14]. Total RNA was extracted from batches of 8-10 female mosquitoes using the Ambion RNA4PCR kit. RNA was labelled with cy3 and cy5 dyes and hybridised to the microarray chip according to the protocol described previously [14]. RNA and cRNA quantity and quality were assessed using a Nano- 
drop spectrophotometer (Nano-drop Technologies) and Bioanalyser (Agilent) respectively.

\section{Microarray analysis}

The direct comparison between PEM and MOZ was analysed using GeneSpring v.11.5 (Agilent) which applies a standard t-test to normalised raw fluorescence values. Following normalisation with LIMMA [23] the MAANOVA package in $\mathrm{R}$ [24] was applied to the loop design as used previously [14]. The two independent experiments from 2011 and 2012 were considered together, providing independent datasets from which improved confidence in identifying genuine candidate genes could be made. Probes were filtered based on the hypothesis of significance $(\mathrm{q}<0.05)$ and under the hypothesis that expression should be consistently greater in the resistant compared to the susceptible populations (i.e. PEM > UNG/ DAR). Microarray data are available in the ArrayExpress database (www.ebi.ac.uk/arrayexpress) under accession number E-MTAB-2075 (PEM vs. MOZ direct comparison) and E-MTAB-2074 (PEM vs. UNG/DAR loop design).

\section{Patterns of resistance-associated gene expression on Zanzibar}

The expression levels of candidate genes for pyrethroid resistance from the microarray analysis were assessed using quantitative reverse transcription PCR (qRT-PCR) following the MIQE guidelines [25].

qPCR was performed on mosquitoes collected from 2012 and 2013 with three objectives:

I. To independently validate gene expression in $A n$. arabiensis from 2012 in the microarray experiments.

II. To determine gene expression patterns of candidate genes from Pemba and Unguja in collections made in 2013.

III.To independently validate the expression of a subset of genes up-regulated in Pemba which are putatively part of the hydrocarbon synthesis pathway.

Whole female mosquitoes were collected $24 \mathrm{~h}$ postexposure to insecticide or non-treated papers, briefly chilled (10-20 $\mathrm{min}$ ) and stored in RNAlater according to the manufacturer's instructions. Total RNA was extracted from An. arabiensis using PicoPure ${ }^{\bullet}$ RNA Isolation Kit (Invitrogen) and treated with DNase I (Qiagen). Three biological replicates of RNA extracted from ten mosquitoes were used for the 2012 samples to replicate the microarray experiments. The following year, fourfive biological replicates of five mosquitoes per RNA sample were used. RNA quantity and quality was checked using a Nano-Drop spectrophotometer (Nanodrop Technologies) and Bioanalyser (Agilent) respectively. cDNA was synthesised from $\sim 0.5-1 \mu \mathrm{g}$ of RNA using oligo $(\mathrm{dT})_{20}(50 \mu \mathrm{M})$ and SuperScript III (200 U) (Invitrogen) and purified through a DNA-binding column (Qiagen).

Multiple pairs of exon-exon spanning primers for target and control genes were designed in silico against the Anopheles gambiae PEST sequence (Taxon ID 180454) using primer-BLAST (NCBI). The PCR efficiency, dynamic range and specificity of the primer pair were calculated from running a standard curve over a five-fold dilution series (input cDNA from $\times 5^{-1}$ to $\times 5^{-5}$ ). The primer sequences, amplicon length, efficiencies and gene location are given in Additional file 1.

PCR reactions $(20 \mu \mathrm{l})$ were performed on the MXPro qPCR system (Agilent) with $10 \mu \mathrm{l}$ Brilliant III SYBR Green (Agilent), $300 \mathrm{nM}$ of primers, $2.5 \mu \mathrm{l}$ of input cDNA (diluted 100-fold) and the total volume made up with sterile-distilled water. The thermal profile used throughout consisted of $95^{\circ} \mathrm{C}$ for $10 \mathrm{~min}$ followed by 40 cycles of $95^{\circ} \mathrm{C}$ for $10 \mathrm{~s}$ and $60^{\circ} \mathrm{C}$ for $10 \mathrm{~s}$. Melt curves were run after each PCR to ensure the specificity of the amplified products. Three technical replicates were run for each sample and no template controls were run for each gene.

\section{Data analysis of gene expression}

The data were pre-processed prior to analysis. A Cq value of 35 was considered our limit of detection (LOD) and any samples that failed to amplify above this threshold were given a value of 35 . Outliers were defined as those values which give a standard deviation above 0.5 from the three technical replicates and were removed from the dataset.

Once pre-processed the Cq values were adjusted according to the efficiency of the primer pair. The qPCR repeats were averaged and data normalised against the average values for the ribosomal S7 protein (AGAP010592) and ubiquitin (AGAP007927). The relative quantities of each sample were calculated and log-transformed to normalise the distribution of the data for parametric statistical analysis [26]. A one-sided t-test at $\mathrm{p}<0.05$ was used to assign significance between treatments.

\section{Copy number analysis of P450 candidates}

Several insects have adapted to selection from insecticides by evolving variations in gene copy number (otherwise known as copy number variation (CNV)) (reviewed in [27]). Quantitative PCR (qPCR) using SYBR Green was used to determine whether the elevated expression of CYP4G16, CYP6Z2, and CYP6Z3 in An. arabiensis from Pemba is due to gene amplification. The quantity of genomic DNA (gDNA) extracted from individual $A n$. arabiensis from Unguja and Pemba was analysed using a PicoGreen ${ }^{\circ}$ assay [28] and diluted to $1 \mathrm{ng} / \mu \mathrm{l}$. Internal exonic primers were designed for the target genes 
CYP4G16, CYP6Z2 and CYP6Z3 and for two internal reference genes, elongation factor (AGAP005128) and glucose-6-phosphate dehydrogenase (AGAP010739) (Additional file 1). The efficiency, dynamic range and specificity of each primer pair were assessed by performing a standard curve on a dilution series of DNA (five-fold dilutions from $\times 5^{-1}$ to $\times 5^{-5}$ ). SYBR Green $q P C R$ reactions were performed on the Stratagene MXPro using the exact same conditions as RT-qPCR (see above) with the exception that $2.5 \mu \mathrm{l}$ input gDNA was added to each reaction. To improve the power of detecting a real difference in copy number between resistant and susceptible mosquitoes, copy number analysis was performed on eight individual An. arabiensis which died at the lowest concentrations of insecticide exposure (0.001-0.005\% $\lambda$-cyhalothrin) from Unguja and ten individuals which survived the highest concentrations $(0.1-0.2 \% \lambda$-cyhalothrin) from Pemba. The average gene copy number was calculated using the $\Delta \Delta \mathrm{Cq}$ method described previously [29].

\section{Sodium channel sequencing}

Exon 20 of the sodium channel harbours key residues for pyrethroid and DDT binding in the so-called 'binding pocket' and mutations in this region confer resistance in other insect pests [30]. To determine whether pyrethroid resistance was due to previously unidentified SNPs in this region of $A n$. arabiensis, a $\sim 400 \mathrm{bp}$ fragment of Exon20 was amplified from gDNA extracted from individuals on Pemba and Unguja collected in 2012. PCR reactions were undertaken in $25 \mu \mathrm{l}$ total volumes consisting of $0.5 \mathrm{U}$ Taq Polymerase (KappaBiosystems), $0.5 \mu \mathrm{ldNTPs}(10 \mathrm{mM})$ and $400 \mathrm{nM}$ of forward and reverse primers. Two alternative splice forms of this exon occur in An. gambiae (Exon c/d) and two sets of primer pairs were designed in flanking introns to amplify each variant (Additional file 1). Thermal cycling parameters were $95^{\circ} \mathrm{C}$ for $2 \mathrm{~min}$ followed by 40 cycles of $95^{\circ} \mathrm{C}$ for $30 \mathrm{~s}, 55^{\circ} \mathrm{C}$ for $30 \mathrm{~s}$, and $72^{\circ} \mathrm{C}$ for $30 \mathrm{~s}$ and a final extension step of $72^{\circ} \mathrm{C}$ for 5 mins. Samples for sequencing were performed by Macrogen (Amsterdam) with the forward and reverse primers used as the sequencing primers.

\section{CYP4G16 cloning and sequencing}

The full length CYP4G16 was amplified from cDNA synthesised from pools of five $A n$. arabiensis individuals from Pujini (Pemba) and Mwera (Unguja). The PCR products were amplified using the forward and reverse primers AGAP001076_F1/R1 (Additional file 1) and cloned into the pJET 1.2/blunt cloning vector (Fermentas). Two clones from each strain were sequenced (Core Genomic Facility, University of Sheffield) with the pJET forward and reverse primers as well as three nested forward primers (AGAP001076_F2/F3/F4) (Additional file 1).

\section{Results}

Study area and current distribution of An. gambiae complex on Zanzibar

According to the sites we visited during the study (Figure 1) An. arabiensis is the dominant vector on Zanzibar (Table 1). The exception was in Kilimani, situated within

Table 1 Species identification of a subset of An. gambiae s.l. collected between 2011 and 2013 on Zanzibar

\begin{tabular}{|c|c|c|c|c|c|c|c|c|c|c|c|}
\hline Year & Island & Site & $\begin{array}{l}\text { No. } \\
\text { tested }\end{array}$ & $\begin{array}{l}\text { An. } \\
\text { arabiensis }\end{array}$ & $\begin{array}{l}\% \text { An. } \\
\text { arabiensis }\end{array}$ & $\begin{array}{l}\text { An. } \\
\text { merus }\end{array}$ & $\begin{array}{l}\% \text { An. } \\
\text { merus }\end{array}$ & $\begin{array}{l}\text { An. } \\
\text { gambiae }\end{array}$ & $\begin{array}{l}\% \text { An. } \\
\text { gambiae }\end{array}$ & $\begin{array}{l}\text { An. } \\
\text { quad* }\end{array}$ & $\begin{array}{l}\% \text { An. } \\
\text { quad }^{*}\end{array}$ \\
\hline \multirow[t]{4}{*}{2011} & Unguja & Kilimani & 78 & 13 & 16.7 & 12 & 15.4 & 53 & 67.9 & 0 & 0.0 \\
\hline & Pemba & Chwale & 24 & 23 & 95.8 & 0 & 0.0 & 0 & 0.0 & 0 & 0.0 \\
\hline & & Kiungoni & 24 & 24 & 100.0 & 0 & 0.0 & 0 & 0.0 & 0 & 0.0 \\
\hline & & Uwandani & 24 & 24 & 100.0 & 0 & 0.0 & 0 & 0.0 & 0 & 0.0 \\
\hline \multirow[t]{4}{*}{2012} & Unguja & Chuini & 72 & 72 & 100.0 & 0 & 0.0 & 0 & 0.0 & 0 & 0.0 \\
\hline & & Mwera & 110 & 110 & 100.0 & 0 & 0.0 & 0 & 0.0 & 0 & 0.0 \\
\hline & Pemba & Tumbe & 340 & 206 & 60.6 & 134 & 39.4 & 0 & 0.0 & 0 & 0.0 \\
\hline & & Mangwena & 286 & 284 & 99.3 & 4 & 1.4 & 0 & 0.0 & 0 & 0.0 \\
\hline \multirow[t]{8}{*}{2013} & Unguja & Chuini & 102 & 102 & 100.0 & 0 & 0.0 & 0 & 0.0 & 0 & 0.0 \\
\hline & & Mwera & 71 & 71 & 100.0 & 0 & 0.0 & 0 & 0.0 & 0 & 0.0 \\
\hline & & Kilimani & 66 & 66 & 100.0 & 0 & 0.0 & 0 & 0.0 & 0 & 0.0 \\
\hline & & Cheju & 28 & 16 & 57.1 & 0 & 0.0 & 6 & 21.4 & 6 & 21.4 \\
\hline & Pemba & Pujini & 75 & 75 & 100.0 & 0 & 0.0 & 0 & 0.0 & 0 & 0.0 \\
\hline & & Kiungoni & 92 & 92 & 100.0 & 0 & 0.0 & 0 & 0.0 & 0 & 0.0 \\
\hline & & Uwandani & 69 & 69 & 100.0 & 0 & 0.0 & 0 & 0.0 & 0 & 0.0 \\
\hline & & Tumbe & 71 & 70 & 98.6 & 0 & 0.0 & 1 & 1.4 & 0 & 0.0 \\
\hline
\end{tabular}

*Anopheles quadriannulatus. 
the main urban area of Stone Town and adjacent to the coast, where we identified 68\% An. gambiae s.s., $17 \%$ An. arabiensis and 15\% An. merus in 2011. Two years later all mosquitoes were scored as $A n$. arabiensis from this site $(\mathrm{N}=66)$. In Tumbe, on the north coast of Pemba, 39\% of Anopheles were typed as An. merus $(\mathrm{N}=134)$ consistent with their salt-water adaptation. However, the following year, we did not identify a single $A n$. merus from Tumbe $(\mathrm{N}=71)$; 98\% samples from this site were An. arabiensis, 2\% An. gambiae.
Insecticide resistance and synergism

Following the emergence of pyrethroid resistance on Pemba [17] we generated lambda-cyhalothrin $\mathrm{LC}_{50}$ curves from two sites on each island to quantify the scale of the resistance phenotype between the islands (Figure 2; Additional file 2). The $\mathrm{LC}_{50}$ s from Pemba $(($ Mangwena $=0.121 \%(95 \% \mathrm{CI}=0.080-0.184)$ and Tumbe $=$ $0.092 \%(95 \% \quad \mathrm{CI}=0.060-0.141 \%)$ were a magnitude greater than those from Unguja ( $($ Mwera $=0.007 \%(95 \%$ $\mathrm{CI}=0.005-0.010 \%)$ and Chuini $=0.009 \%(95 \% \mathrm{CI}=0.007-$

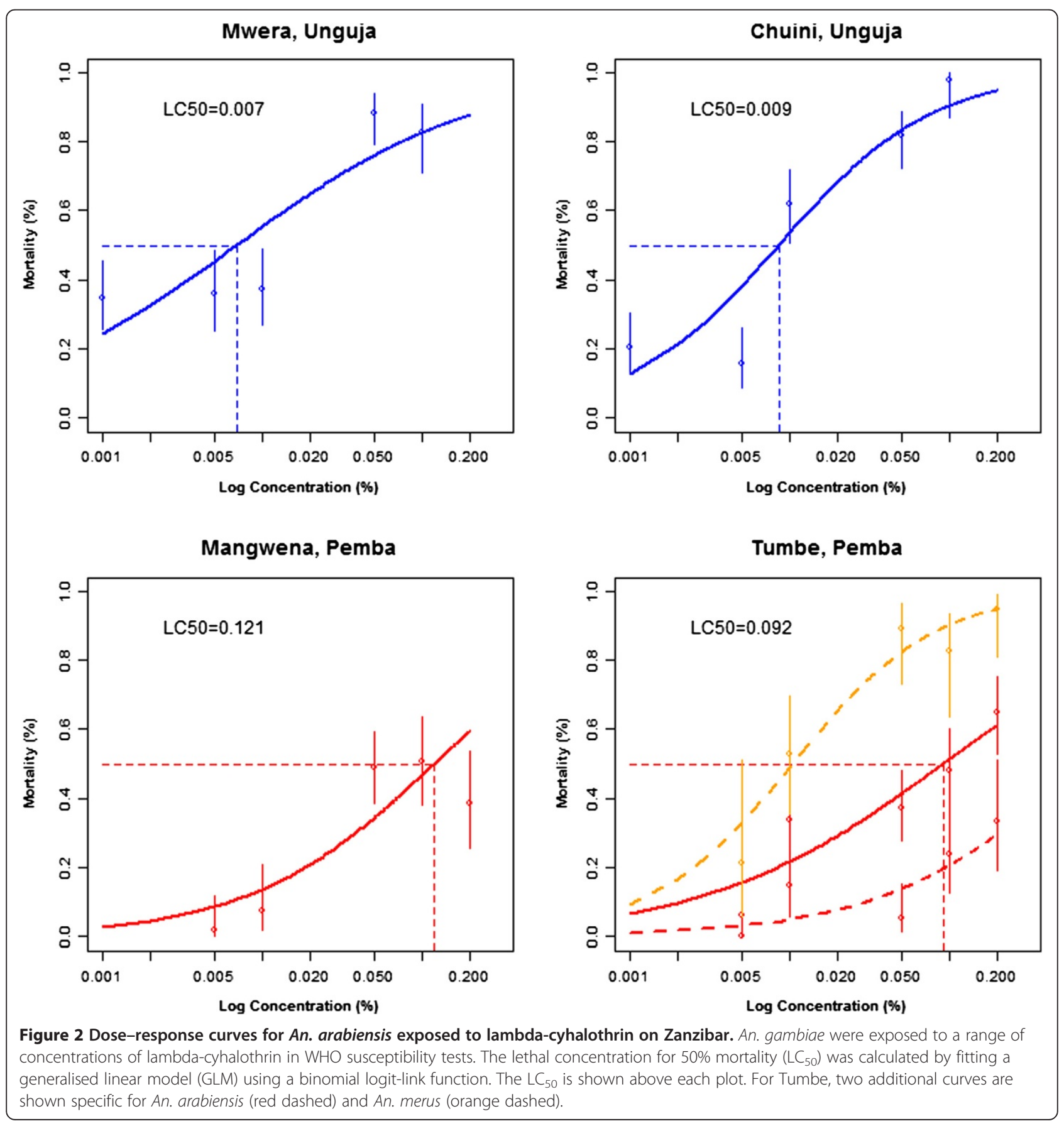


$0.011 \%)$ ) giving resistance ratios of between 10 and 17 -fold. A re-assessment of the data from Tumbe showed that $A n$. merus were markedly more sensitive to lambda-cyhalothrin displaying an $\mathrm{LC}_{50}$ closer to that of $\mathrm{An}$. arabiensis from Unguja ( $\mathrm{LC}_{50}=0.010 \%$; $95 \% \mathrm{CI}=0.006-0.018 \%$ ) (Figure 2).

In addition to the dose-response curves $1125 \mathrm{An}$. gambiae were tested against the WHO diagnostic dose of lambda-cyhalothrin (0.05\%) in susceptibility bioassays in 2011 and 2013 (Figure 3; Additional file 2). WHOdefined resistance (less than $90 \%$ mortality [18]) was observed throughout the study in all sites from Pemba (Figure 3). The lowest mortalities observed were from Chwale in 2011 (19.0\%; 95\% CI =12.1-28.3) and Pujini in 2013 (18.3\%; 95\% CI 11.3-27.9\%). Although these data indicate that resistance remains particularly strong on Pemba, significantly higher mortality levels were observed in three out of the four sites tested on Pemba in 2013 compared with Pujini ( $\chi^{2} \mathrm{p}<0.001$ for each pair-wise comparison). This suggests that resistance may not be homogeneously expressed across the island. In Kiungoni, mortality to lambda-cyhalothrin approximately doubled between 2011 and 2013 indicating that in this site at least that resistance decreased over the three year study period.

As reported earlier [17], An. arabiensis from Unguja were susceptible to pyrethroids at the start of this study (2011). However, resistance had emerged on the island (81.9\% - 88.4\% mortality) in 2012. In the subsequent year, further reductions in mortality were observed in Chuini (45.7\%; 95\% CI 36.1-55.7\%) and Mwera (67.0\%; 95\% CI 57.1-75.6\%) confirming that resistance had arisen during the course of the study.

Synergist assays with piperonyl butoxide (PBO 4\%), a general inhibitor of P450 monooxygenases, completely restored susceptibility to lambda-cyhalothrin in Unguja and Pemba (mortality $=96-100 \%$ ) (Figure 3 ). This suggests that $\mathrm{P} 450 \mathrm{~s}$ may contribute towards the resistance phenotype we observe in An. arabiensis. Unfortunately, due to a restricted number of insects available, we were only able to perform one set of assays using DDT but the 2011 data do suggest potential cross-resistance in Pemba (Kiungoni, 78.8\% mortality).

Finally, the carbamate bendiocarb has recently replaced lambda-cyhalothrin in IRS on Zanzibar [17] and our bioassay data show that all mosquitoes tested to date are completely susceptible to this insecticide (100\% mortality, Unguja $\mathrm{N}=57$; Pemba $\mathrm{N}=192$; Additional file 2).

\section{Existing target-site markers for pyrethroid resistance}

A sub-sample of Anopheles were screened for the $k d r$ target site mutations (1014 F and 1014S) and ace-1R. None of these known resistance alleles were found over the three year period (Unguja $\mathrm{N}=120$; Pemba $\mathrm{N}=251$ ). Sequencing exon 20 of the sodium channel which harbours target-site mutations in other insects [30] failed to identify any additional non-synonymous mutations suggesting that alternative mechanisms underlie the pyrethroid resistance phenotype in $A n$. arabiensis from Zanzibar.

\section{Gene expression in An. arabiensis from Pemba Island}

A direct comparison of the adult transcriptome between An. arabiensis collected from Pemba in 2011 and a susceptible laboratory colony originating from Mozambique (MOZ) yielded 2214 probes significantly differentially expressed (1071 up (48.3\%); 1143 down (51.7\%)) (Additional file 3). This large number of probes and the extremely high fold changes at the ends of the expression distribution most probably reflect genetic divergence between the field and laboratory strains. We therefore do not consider this experiment in isolation; however, under the assumption that the mechanism responsible for pyrethroid resistance was the same in 2011 and 2012, this data set was combined with a second experiment conducted in 2012 on An. arabiensis from Pemba (PEM), Unguja (UNG) and pyrethroid-susceptible 
mosquitoes from Dar es Salaam (DAR). Using the 2214 probes from the 2011 experiment as our initial probe list, we subsequently filtered probes based on the hypothesis of significance in each pair-wise comparison (false discovery rate $(\mathrm{FDR})$ adjusted $\mathrm{p}$-value $<0.05)$ and greater expression in the resistant strain PEM compared to UNG and DAR $(\mathrm{N}=2645)$. This left just 268 probes representing 208 unique transcripts (Additional file 3).

The most over-expressed transcript in the PEM vs DAR comparison was CYP4G16 (AGAP001076-RA) (fold-change $(\mathrm{FC})=5.4)$. CYP4G16 has four alternatively spliced transcripts and probes specific for each of these were among those most highly expressed in PEM against DAR (average FC $=4.4$ ) and UNG $(\mathrm{FC}=2.0$ ) (Figure 4).

The most over-expressed transcripts in PEM compared to UNG included a Niemann-pick type c gene (AGAP002852RA), two transcripts for enzymes involved with 5' nucleotidase activity (AGAP005457-RA \& AGAP005458-RA) and the alkaline phosphatase (AGAP001684-RA) and the P450 CYP6Z2 (AGAP008218-RA) (Additional file 3). Two members of the CYP6Z family of P450s were overexpressed in all three PEM comparison and showed higher expression against UNG than samples from DAR; CYP6Z2 (FC $=2.6$ vs. 1.6) and $C Y P 6 Z 3$ ( $F C=1.9$ vs. 1.6) (AGAP008217-RA). Members of this class of $C Y P$ genes have been associated with pyrethroid resistance previously [31,32].

Functional annotation of the 268 candidate probes with the DAVID analysis software tool [33] yielded no significantly enriched biological terms. Under the stringent filtering strategy used here there is a strong possibility of missing genes or biological processes involved with the resistance phenotype. Therefore, we ran a DAVID analysis on common probes over-expressed in the resistant mosquitoes from the 2012 experiment only $(\mathrm{N}=2645)$ (Additional file 3). Following multiple hypothesis testing the most enriched cluster of genes was associated with P450 metabolism (enrichment score $(E S)=4.55$ ), mitochondrial processes $(E S=3.93)$ and ribosomal genes $(E S=3.36)$ (Additional file 4). A look at individual genes solely from the 2012 analysis found that no additional P450s were contained within the PEM over expressed subset than those already described above.

\section{Validation of candidate gene expression in Zanzibar}

Independent validation of expression data from highthroughput transcriptomic studies is a necessary step towards identifying and verifying candidate genes. Based on our final list of candidates we took six target genes forward for reverse-transcription quantitative PCR (RTqPCR); the P450s CYP4G16, CYP6Z2 and CYP6Z3 along with three genes with putative involvement as part of a hydrocarbon synthesis pathway, acyl-coa thioesterase (AGAP003848), acyl-coa dehydrogenase (AGAP005662) and 3-hydroxyacyl-coa dehydrogenase (AGAP007784).

RT-qPCR on An. arabiensis collected in 2012 from Mangwena (the same site used in the microarray analysis) confirmed a significant over-expression of CYP4G16 in Pemba compared to Unguja $(\mathrm{ddCt}=5.5 ; \mathrm{p}<0.014)$ but could not validate the over-expression of CYP6Z2 $(\mathrm{ddCt}=1.5 ; \mathrm{p}=0.127)$ or CYP6Z3 $(\mathrm{ddCt}=0.9 ; \mathrm{p}=0.206)$ (Figure 5A).
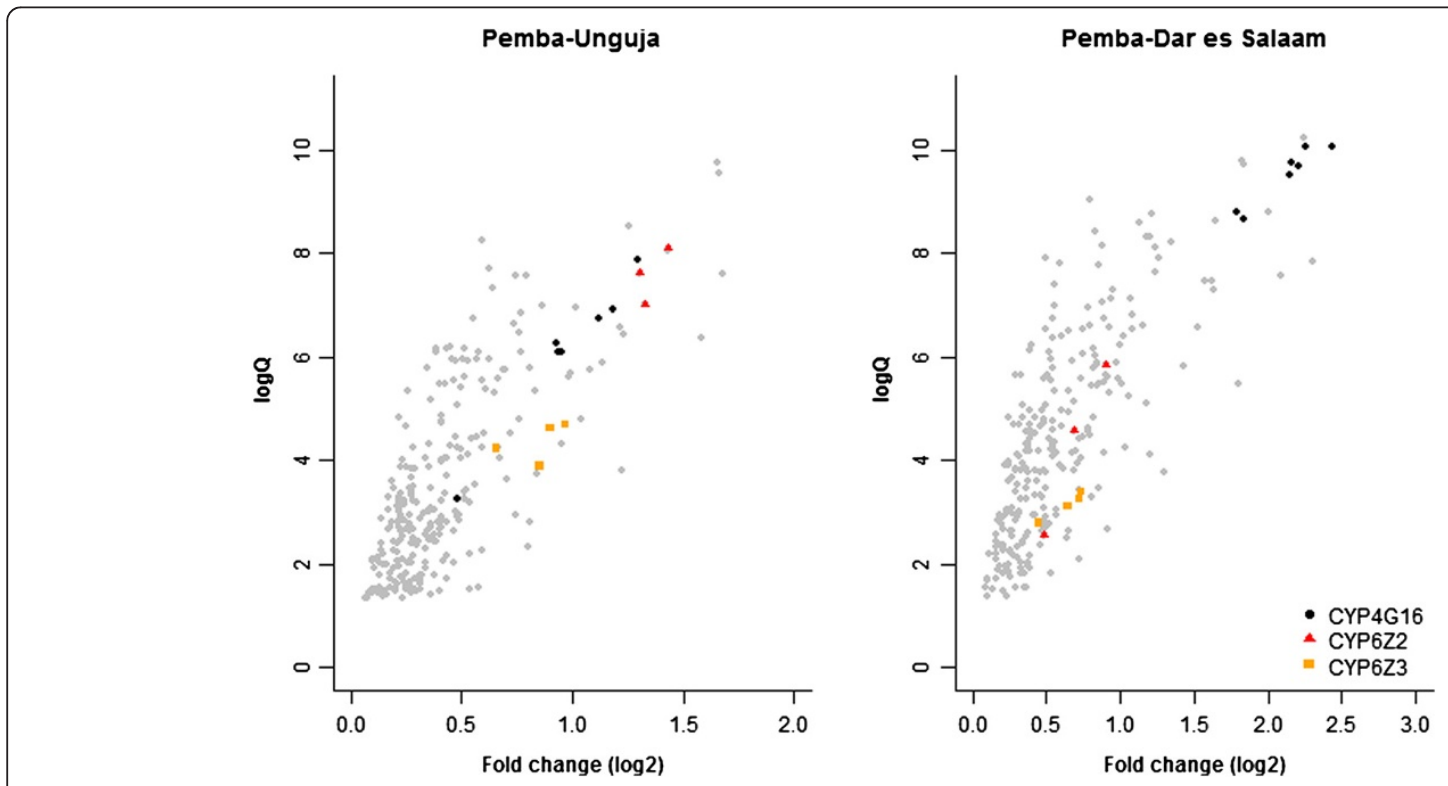

Figure 4 Volcano plots for expression between An. arabiensis from Pemba against samples from Dar es Salaam and Unguja. Expression plots for the 268 candidate probes significantly up-regulated in (i) An. arabiensis from Pemba collected in 2012 against UNG and (ii) DAR. Probes for the three candidate P450s are highlighted on each plot. 


\section{A}

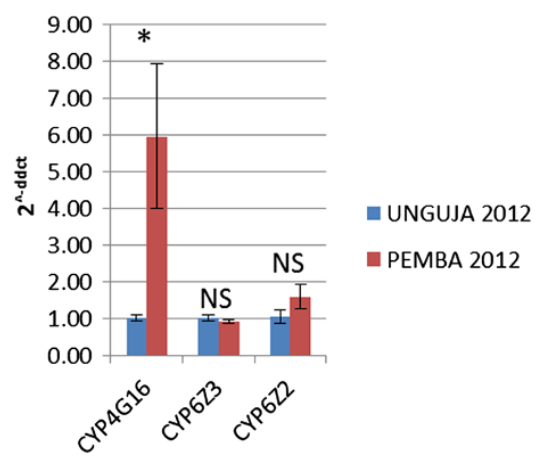

B

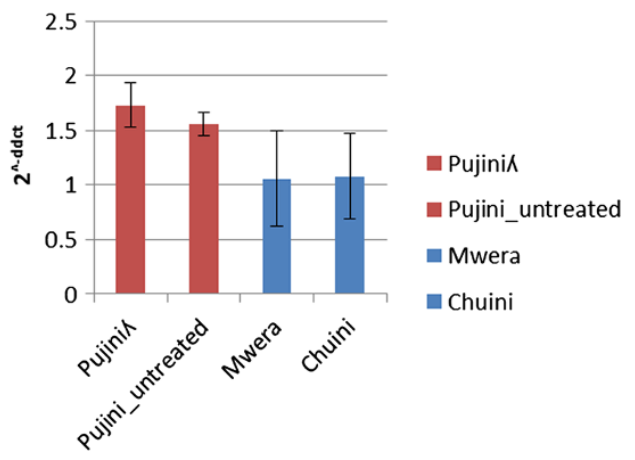

Figure 5 Quantitative PCR validation of candidate P450s in An. arabiensis from Zanzibar. A) Quantitative PCR (qPCR) analysis of CYP4G16, CYP6Z2 and CYP6Z3 was performed on An. arabiensis collected from Pemba (Mangwena) and Unguja (Chuini \& Mwera) in 2012. The mean \pm SEM for three ddCq values relative to Unguja are presented. (B) CYP4G16 expression in An. arabiensis collected in 2013 . Four groups of mosquitoes were included in the analysis: (i) Pujini exposed to lambda-cyhalothrin (0.05\%) (Pujini $\lambda$ ) (ii) Pujini unexposed to insecticide (Pujini_untreated) (iii) Mwera (iv) Chuini. The mean ddCq values \pm SEM of five biological replicates are presented. NS $=$ non-significant. ${ }^{*} \mathrm{p}<0.05$ one-sided Student's t-test.

In 2013, we collected mosquitoes in RNAlater from two sites on Unguja (Mwera and Chuini) and from the most resistant site on Pemba, Pujini. When we compare expression against An. arabiensis from Mwera - the least resistant site in 2013 (mortality to lambda-cyhalothrin 67.0\%) - RT-qPCR estimated a 1.6- and 1.5-fold increase in CYP4G16 in lambda-cyhalothrin-treated and non-treated mosquitoes respectively although neither difference was significant $(\mathrm{p}>0.05)$ (Figure $5 \mathrm{~B}$ ). This is approximately a quarter of the difference in expression observed between samples taken from Pemba and Unguja in 2012 (Figure 5A) and could represent the increase of pyrethroid resistance in Unguja by our sampling period in 2013.

Three genes with putative involvement in hydrocarbon synthesis which passed our filtering criteria in the microarray analysis (acyl-coa thioesterase, acyl-coa dehydrogenase, hydroxyacyl-coa dehydrogenase) were analysed by qPCR on An. arabiensis collected in 2013. The patterns of up-regulation in Pemba were extremely similar between those detected through the microarray in 2012 and those analysed by qPCR in 2013 (Figure 6). This provides further independent validation of the array experiments and suggests that these genes could be co-expressed with CYP4G16 as part of the hydrocarbon synthesis pathway.

\section{Copy number variation of P450 candidates}

Copy number analysis of the three major candidate genes CYP6Z2, CYP6Z3 and CYP4G16 was performed on $A n$. arabiensis from Pemba surviving the higher doses of lambda-cyhalothrin compared to susceptible counterparts from Unguja. None of the candidate genes showed any significant difference between the two groups and so the increase in expression observed in the microarrays is unlikely explained by copy number changes (Additional file 5).

\section{Discussion}

While national malaria control programmes targeting indoor resting/biting mosquitoes have enjoyed success at reducing malaria in recent years, this success has brought with it many challenges for the future of vector control including: a) the selection of physiological resistance [2], b) a change in Anopheles biting and resting habits [34] and c) shifts in the composition of vector species [35]. The evidence presented previously [17] and in this study suggests that at least two of these are threatening malaria control in Zanzibar.

Anopheles arabiensis has supplanted An. gambiae s.s. as the major vector in many parts of East Africa where the two species are sympatric [36,37]. In the 1960s, it was reported that $A n$. arabiensis had replaced An. gambiae s.s. as the major vector on Zanzibar following DDT spraying as part of the Global Malaria Eradication Programme [38] although by the 1990s, An. gambiae s.s. had re-established itself as the main vector on Zanzibar [39]. The data presented here and in a previous publication [17] suggest that history is repeating itself, with $A n$. arabiensis remerging as the dominant vector following the implementation of a scaled-up vector control programme. Pockets of An. gambiae s.s. and $A n$. merus were found in sites proximate to the coast (e.g. Kilimani (Unguja) and Tumbe (Pemba)) but only a few $A n$. gambiae $(\mathrm{N}=7)$ and no $A n$. merus were identified in 2013. It is worth noting that our sampling strategy was restricted to collecting larvae from breeding pools and it important to broaden these collections to collect adult vectors indoors and outdoors, and screen these for the presence of Plasmodium before drawing 


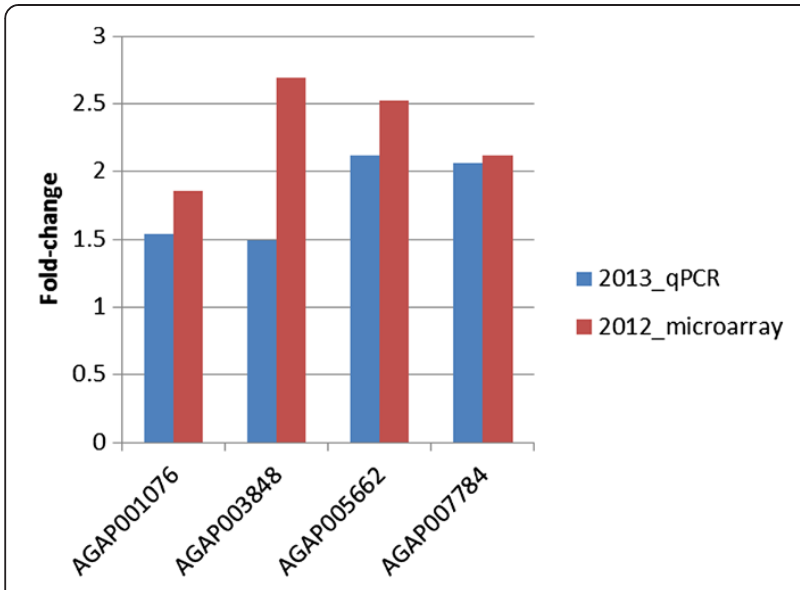

Figure 6 Co-expression of CYP4G16 with genes significantly up-regulated in Pemba associated with fatty-acid metabolism. The expression levels between Pemba and Unguja are compared from those in the microarrays performed on 2012 collected An. arabiensis samples against those from qPCR performed on 2013 samples. For the 2013 qPCR data, the fold-changes are calculated from $d d C q(P e m b a) / d d C q($ Unguja).

conclusions on the role of alternative vectors in contributing to the residual transmission on Zanzibar.

Pyrethroid resistance is now present throughout the entire Zanzibar archipelago. In a previous study conducted in 2010-2011, resistance was detected solely in An. arabiensis from Pemba suggesting that differential selective forces were acting on the two islands. However, we have subsequently shown that the proportion of mosquitoes surviving exposure to lambda-cyhalothrin $(0.05 \%)$ increased approximately 3-fold in Unguja between 2012 and 2013. This rise within a single year highlights how swift the spread and selection of resistance can occur.

At present, it is difficult to determine the origins of resistance on Zanzibar. Pemba and Unguja are separated by a $50 \mathrm{~km}$ strip of the Indian Ocean and large numbers of human traffic moving between the two islands provide a passive route for migration of anopheline mosquitoes. Similarly, it is feasible that resistance could have emerged independently on Unguja. Resolving the genetic differentiation of Anopheles between Unguja and Pemba would not only provide information on the spread of resistance traits but present estimates of the diversity and effective population sizes as measures of vector control success. Regardless of the origin, resistance management strategies should be implemented equally on both islands to curb further selection.

In bioassays conducted on Pemba we observed WHOdefined resistance (less than $90 \%$ mortality) in all sites tested. Nevertheless, with the exception of Pujini it was noticeable that average resistance levels dropped between 2011 and 2013 with three out of four sites showing mortality over $67 \%$ and large increases in pyrethroid mortality in some sites (e.g. mortality in An. arabiensis to $0.05 \%$ lambda-cyhalothrin was $5.2 \%$ in Tumbe in 2012 but increased to $77.1 \%$ the following year). The vast majority of insects tested in these sites were $A n$. arabiensis and therefore any increase cannot be attributed to species differences. It is also difficult to ascribe the differences in resistance levels across Pemba to experimental variation as we were careful to record the age of mosquito, as well as room temperature and humidity throughout - factors which can greatly influence mortality in bioassays [18].

It is possible that the change in insecticide use in IRS, from pyrethroids to carbamates may have contributed to the reduction in pyrethroid resistance. However, further rounds of bioassays, and an analysis of the strength of the resistance, via repeat determination of the LC50, is needed before it can be concluded that pyrethroid resistance has declined since the introduction of bendiocarb for IRS.

In response to the discovery of pyrethroid resistance on Zanzibar we set out to identify the underlying mechanisms in An. arabiensis to support future resistance management strategies. We performed two separate microarray experiments using stringent criteria to filter out probes based on significant over-expression in $A n$. arabiensis from Pemba. This yielded just 208 transcripts and of these, replicate probes for three specific P450s (CYP6Z2, CYP6Z3 and CYP4G16) previously implicated in other resistance studies in An. gambiae were among the most over-transcribed genes.

The P450, CYP4G16 was up-regulated in resistant $A n$. arabiensis approximately 4.5 - and 2.0-fold compared to DAR and UNG respectively. Although these are fairly modest changes in expression they were among the highest observed in the comparison of the field populations. qPCR analysis gave an estimated 6-fold difference between An. arabiensis from Pemba compared to Unguja. Elevated expression levels of this enzyme were observed in families of An. arabiensis displaying an increased tolerance to deltamethrin in Northern Cameroon [40]. A modest foldchange increase was observed in a laboratory resistant strain of An. arabiensis from Sudan using qPCR although this was not backed-up by the microarray data in the same study [41].

CYP4G16 is an alternatively spliced gene with four transcripts located on the $\mathrm{X}$ chromosome. Sequencing cloned CYP4G16 from pooled cDNA from Pemba and Unguja revealed no SNPs between the populations and showed that CYP4G16 is an extremely conserved enzyme between An. arabiensis and An. gambiae. The majority of insects only possess two CYP4G genes [42]. The other CYP4G gene in An. gambiae, CYP4G17, was also up-regulated in resistant $A n$. arabiensis from Pemba 
(1.9-fold versus DAR; 1.5 -fold versus UNG) but was not significantly expressed in the comparison against MOZ in 2011. CYP4G genes have played a key evolutionary role in the terrestrial adaptation of Insecta by catalysing the final step of cuticular hydrocarbon synthesis and thus providing a protective waterproof layer [42]. The orthologue of CYP4G17 in Drosophila melanogaster (DmCYP4G1) catalyses an oxidative decarbonylation of long-chain aldehydes, which serves as the final step of hydrocarbon synthesis from long-chain fatty acids in insects [43]. Synthesis of cuticular hydrocarbons from longchain fatty acids is complex and requires a suite of elongases, reductases and dehydrogenases [44]. It is therefore of interest that the final list of candidates from the microarray analysis included several genes involved in fatty-acid metabolism; acyl-coa thioesterase, acyl-coa dehydrogenase, hydroxyacyl-coa dehyrogenase, and over expression of these was confirmed in An. arabiensis collected in 2013 by qPCR. DmCYP4G1 is highly expressed in the fat body and carcass of male and female $D$. melanogaster whereas the orthologue of CYP4G16, DmCYP4G15, is expressed in the thoraic-abdominal ganglion [45]. Tissue specific expression in An. gambiae shows that both CYP4G genes are over expressed in the insect abdomen consistent with hydrocarbon synthesis in oenocytes (Ranson et al. unpublished; MozAtlas [46]). In the German cockroach, Blatella germanica, CYP4G19 was over-expressed five-fold in a pyrethroid resistant strain and expression was found to be greater in the abdomen than the head or thorax [47]. Cuticular-based resistance has been reported from several agricultural and medically important insects [48-50] with the over-expression of specific genes implicated in some cases [51,52]. However, whilst the up-regulation of CYP4G16 does suggest a potential role for cuticular based resistance in An. arabiensis in Zanzibar, it is important to recognise that the functional work to validate this hypothesis is still underway. Whether or not PBO can synergise pyrethroids (and other insecticides) by inhibiting P450s essential to cuticular formation also needs further investigation.

In contrast to target site resistance, where a single mutation can confer high levels of resistance [10] there is increasing evidence that insecticide resistance in Anopheles may not be underpinned by one single gene but by a suite of co-regulated enzymes in a more intricate pathway depending on the population. One example is the CYP6Z family in which members are over-expressed in pyrethroid resistant $A n$. gambiae [31,32]. Functional work in these enzymes has found that they are unable to metabolise pyrethroids directly but instead, that they play a role in the clearance of pyrethroid metabolites. We propose that the coordinated up-regulation of multiple genes involved in $\mathrm{CHC}$ biosynthesis is a putative resistance mechanism underpinning the pyrethroid resistance in An. arabiensis in Zanzibar.
The association of P450s with resistance on Zanzibar is supported by the near full restoration of pyrethroid susceptibility we observed in the PBO assays. PBO has been incorporated into a new generation of LLINs alongside pyrethroids to combat resistance [53]. While a wider adoption of these nets as IRM tools is restricted at present, given the resistance phenotype described in $A n$. arabiensis in this study (i.e. over-expression of P450s with no $k d r$ ), it would be interesting to determine their effectiveness against wild caught mosquitoes on Zanzibar as a possible option for resistance management.

Pyrethroid resistance in An. arabiensis remains patchy in both its distribution and severity in East Africa. A common phenotype in $A n$. arabiensis of resistance to pyrethroids with no cross-resistance to DDT has now appeared in southern Uganda on the shores of Lake Victoria [54], in the Northern highlands of lower Moshi in mainland Tanzania [7]. There is evidence for a similar but milder resistant phenotype from Western Kenya [55]. The presence of DDT resistance on Pemba in 2011 suggests that the resistance phenotype on Zanzibar differs to that on the mainland. An additional bioassay conducted during the dry season (October) on Pemba in 2013 confirms this finding (63.0\% mortality; Additional file 2) and indicates that DDT resistance has remained relatively stable between 2011 and 2013. At present there is no evidence to suggest that $k d r$ plays a role in any of these regions and in this study, a large screen for 1014 $\mathrm{F}$ and 1014S $(\mathrm{N}=371)$ as well as sequencing regions of the sodium channel where alternative $k d r$ variants exist in other insect pests, provided no evidence to suggest the contrary. Whether a single mechanism of resistance in An. arabiensis is sweeping across the East African region or independent selection events are taking place is currently unknown. Future population genetic approaches in An. arabiensis from Zanzibar and a wider geographical region will no doubt provide clues on the spread of this resistance phenotype.

\section{Conclusion}

Insecticide resistance in malaria vectors is seen as a significant hurdle to malaria elimination in Africa. There are a few well cited examples of operational failure as a consequence of resistance and experimental evidence is gathering to show that LLINs and/or IRS are not adequately killing resistant vectors [56,57]. Haji et al. (2013) and colleagues have already shown that resistance has a significant operational impact on the effectiveness of LLINs and IRS and warned about its potential negative effects on Zanzibar highlighting the importance of resistance management. Important proactive steps have been swiftly taken to address this issue on Zanzibar with the switch to alternative modes of action for targeted IRS. The plasticity in feeding and resting behaviour of 
An. arabiensis [58] will necessitate additional tools to control this vector. The case of Zanzibar represents an ideal opportunity to systematically monitor resistance, using entomological data and candidate molecular markers (described in this paper), and quantify its impact on our ability to control mosquito vectors.

\section{Additional files}

Additional file 1: PCR and quantitative PCR (qPCR) primer
information.
Additional file 2: WHO susceptibility bioassay data.
Additional file 3: Microarray gene expression data.
Additional file 4: Cluster analysis of common candidate genes
over-expressed in microarrays using DAVID software.
Additional file 5: Copy number analysis of CYP4G16, CYP6Z2 and
CYP6Z3.

\section{Competing interests}

All authors declare that they have no competing interests.

\section{Authors' contributions}

CMJ, GD, SM and HR conceived the study. SM, KAH, BOK, JHM and CMJ planned, supervised and participated in insect collections and insecticide bioassays. JB and MD contributed to the field work and performed the molecular assays as part of their Masters' degrees, supervised by CMJ and HR. ASA facilitated the field work. BK collected and contributed insect material for microarrays. CMJ analysed the data and wrote the first draft of the manuscript. All authors read and approved the final version of the manuscript.

\section{Acknowledgements}

We would like to express our gratitude to Nassor S Nassor, Haji Mwita, Kombo Haji, Badru Badru, Benard Batengana and Abdulhalim Abdallah Omar for assistance with insect collections, rearing and bioassays. We would like to thank Patricia M. Pignatelli for the cloning of CYP4G16. This work was funded by a Hassan Mshinda Career Development Fellowship and partial funding from the European Union Seventh Framework Programme FP7 (2007-2013) under Grant Agreement 265660 AvecNet.

\section{Author details}

${ }^{1}$ Department of Vector Biology, Liverpool School of Tropical Medicine, Pembroke Place, Liverpool L3 5QA, UK. ${ }^{2}$ Zanzibar Malaria Control Programme, Mwanakwerekwe, P.O. Box 407, Stone Town, Zanzibar, Tanzania. ${ }^{3}$ QIMR Berghofer Institute of Medical Research, 300 Herston Road, Herston Brisbane QLD 4006, Australia. ${ }^{4}$ National Institute for Medical Research, Amani Research Centre, P.O. Box 81, Muheza, Tanzania. ${ }^{5}$ Ifakara Health Institute, PO Box 78373, Dar es Salaam, Tanzania.

Received: 11 September 2013 Accepted: 28 November 2013 Published: 6 December 2013

\section{References}

1. WHO Global Malaria Programme: Global plan for insecticide resistance management in malaria vectors (GPIRM). Geneva: World Health Organization; 2012.

2. Ranson H, N'Guessan R, Lines J, Moiroux N, Nkuni Z, Corbel V: Pyrethroid resistance in African anopheline mosquitoes: what are the implications for malaria control? Trends Parasitol 2011, 27:91-97.

3. Edi CVA, Koudou BG, Jones CM, Weetman D, Ranson H: Multiple-insecticide resistance in Anopheles gambiae mosquitoes, Southern Cote d'Ivoire. Emerg Infect Dis 2012, 18(9):1508-1511.

4. Badolo A, Traore A, Jones CM, Sanou A, Flood L, Guelbeogo WM, Ranson H, Sagnon N: Three years of insecticide resistance monitoring in Anopheles gambiae in Burkina Faso: resistance on the rise? Malar J 2012, 11(1):e232.
5. Protopopoff N, Matowo J, Malima R, Kavishe R, Kaaya R, Wright A, West PA, Kleinschmidt I, Kisinza W, Mosha FW, Rowland M: High level of resistance in the mosquito Anopheles gambiae to pyrethroid insecticides and reduced susceptibility to bendiocarb in north-western Tanzania. Malar J 2013, 12:149.

6. Ramphul U, Boase T, Bass C, Okedi LM, Donnelly MJ, Muller P: Insecticide resistance and its association with target-site mutations in natural populations of Anopheles gambiae from eastern Uganda. Trans $R$ Soc Trop Med Hyg 2009, 103(11):1121-1126.

7. Matowo J, Kulkarni MA, Mosha FW, Oxborough RM, Kitau JA, Tenu F, Rowland M: Biochemical basis of permethrin resistance in Anopheles arabiensis from Lower Moshi, north-eastern Tanzania. Malar J 2010, 9:193.

8. Martinez Torres D, Chandre F, Williamson MS, Darriet F, Berge JB, Devonshire AL, Guillet P, Pasteur N, Pauron D: Molecular characterization of pyrethroid knockdown resistance $(k d r)$ in the major malaria vector Anopheles gambiae s.s. Insect Mol Biol 1998, 7(2):179-184.

9. Ranson H, Jensen B, Vulule JM, Wang X, Hemingway J, Collins FHI: Identification of a point mutation in the voltage-gated sodium channel gene of Kenyan Anopheles gambiae associated with resistance to DDT and pyrethroids. Insect Mol Biol 2000, 9(5):491-497.

10. Donnelly MJ, Corbel V, Weetman D, Wilding CS, Williamson MS, Black WC: Does kdr genotype predict insecticide-resistance phenotype in mosquitoes? Trends Parasitol 2009, 25(5):213-219.

11. Witzig C, Parry M, Morgan JC, Irving H, Steven A, Cuamba N, Kerah-Hinzoumbe C, Ranson H, Wondji CS: Genetic mapping identifies a major locus spanning P450 clusters associated with pyrethroid resistance in $k d r$-free Anopheles arabiensis from Chad. Heredity 2013, 110(4):389-397.

12. Wondji CS, Morgan J, Coetzee M, Hunt RH, Steen K, Black WC, Hemingway J, Ranson H: Mapping a Quantitative Trait Locus (QTL) conferring pyrethroid resistance in the African malaria vector Anopheles funestus. BMC Genomics 2007, 34:8.

13. Müller P, Warr E, Stevenson BJ, Pignatelli PM, Morgan JC, Steven A, Yawson AE, Mitchell SN, Ranson H, Hemingway J, et al: Field-caught permethrin-resistant Anopheles gambiae overexpress CYP6P3, a P450 that metabolises pyrethroids. PLoS Genet 2008, 4(11):e1000286.

14. Mitchell S, Stevenson B, Müller P, Wilding C, Yawson A, Field S, Hemingway J, Paine $M$, Ranson $H$, Donnelly M: Identification and validation of a gene causing cross-resistance between insecticide classes in Anopheles gambiae from Ghana. Proc Natl Acad Sci USA 2012, 109:6147-6152.

15. Bhattarai A, Ali AS, Kachur SP, Martensson A, Abbas AK, Khatib R, Al-Mafazy AW, Ramsan M, Rotllant G, Gerstenmaier JF, et al: Impact of artemisinin-based combination therapy and insecticide-treated nets on malaria burden in Zanzibar. PLoS Med 2007, 4(11):1784-1790.

16. Aregawi MW, Ali AS, Al-Mafazy AW, Molteni F, Katikiti S, Warsame M, Njau RJ, Komatsu R, Korenromp E, Hosseini M, et al: Reductions in malaria and anaemia case and death burden at hospitals following scale-up of malaria control in Zanzibar, 1999-2008. Malar J 2011, 10:46.

17. Haji KA, Khatib BO, Smith S, Ali AS, Devine GJ, Coetzee M, Majambere S: Challenges for malaria elimination in Zanzibar: pyrethroid resistance in malaria vectors and poor performance of long-lasting insecticide nets. Parasit Vectors 2013, 6:82.

18. WHO: Test procedures for insecticide resistance monitoring in malaria vector mosquitoes. Geneva: World Health Organistion; 2013.

19. Scott JA, Brogdon WG, Collins FH: Identification of single specimens of the Anopheles gambiae complex by the Polymerase chain reaction. Am J Trop Med Hyg 1993, 49(4):520-529.

20. Bass C, Nikou D, Donnelly MJ, Williamson MS, Ranson H, Ball A, Vontas J, Field LM: Detection of knockdown resistance $(k d r)$ mutations in Anopheles gambiae: a comparison of two new high-throughput assays with existing methods. Malar J 2007, 6:e111.

21. Bass C, Nikou D, Vontas J, Williamson MS, Field LM: Development of high-throughput real-time PCR assays for the identification of insensitive acetylcholinesterase (ace-1(R)) in Anopheles gambiae. Pestic Biochem Phys 2010, 96(2):80-85.

22. Churchill GA: Fundamentals of experimental design for cDNA microarrays. Nat Genet 2002, 32:490-495.

23. Smyth G: Limma: linear models for microarray data. In Bioinformatics and Computational Biology Solutions using $R$ and Bioconductor. Edited by Gentleman R, Carey V, Dudoit S, Irizarry R, Huber W. New York: Springer; 2005:397-420 
24. Wu H, Kerr M, Cui X, Churchill G: MAANOVA: a software package for the analysis of spotted cDNA microarray experiments. In The Analysis of Gene Expression Data. Edited by Parmigiani G, Garrett E, Irizarry R, Zeger S. London: Springer; 2003:313-341.

25. Bustin SA, Benes V, Garson JA, Hellemans J, Huggett J, Kubista M, Mueller R, Nolan T, Pfaffl MW, Shipley GL, Vandesompele J, Wittwer CT: The MIQE guidelines: minimum information for publication of quantitative real-time PCR experiments. Clin Chem 2009, 55(4):611-622.

26. Rieu I, Powers SJ: Real-time quantitative RT-PCR: design, calculations, and statistics. Plant Cell 2009, 21(4):1031-1033.

27. Bass C, Field LM: Gene amplification and insecticide resistance. Pest Manag Sci 2011, 67(8):886-890.

28. Wilding CS, Weetman D, Steen K, Donnelly MJ: Accurate determination of DNA yield from individual mosquitoes for population genomic applications. Insect Sci 2009, 16(4):361-363.

29. Bel Y, Fau Ferre J, Ferre J, Fau Escriche B, Escriche B: Quantitative real-time PCR with SYBR green detection to assess gene duplication in insects: study of gene dosage in Drosophila melanogaster (Diptera) and in Ostrinia nubilalis (Lepidoptera). BMC Res Notes 2005, 4:84.

30. Davies TGE, Field LM, Usherwood PNR, Williamson MS: DDT, pyrethrins, pyrethroids and insect sodium channels. IUBMB Life 2007, 59:151-162.

31. David JP, Strode C, Vontas J, Nikou D, Vaughan A, Pignatelli PM, Louis C, Hemingway J, Ranson H: The Anopheles gambiae detoxification chip: a highly specific microarray to study metabolic-based insecticide resistance in malaria vectors. Proc Natl Acad Sci USA, 102(11):4080-4084.

32. Nikou D, Ranson H, Hemingway Jl: An adult-specific CYP6P450 gene is overexpressed in a pyrethroid-resistant strain of the malaria vector, Anopheles gambiae. Gene 2003, 318:91-102.

33. Huang DW, Sherman BT, Lempicki RA: Systematic and integrative analysis of large gene lists using DAVID bioinformatics resources. Nat Protoc 2009, 4(1):44-57.

34. Russell TL, Govella NJ, Azizi S, Drakeley CJ, Kachur SP, Killeen GF: Increased proportions of outdoor feeding among residual malaria vector populations following increased use of insecticide-treated nets in rural Tanzania. Malar J 2011, 10:80.

35. Kitau J, Oxborough RM, Tungu PK, Matowo J, Malima RC, Magesa SM, Bruce J, Mosha FW, Rowland MW: Species shifts in the Anopheles gambiae complex: do LLINs successfully control Anopheles arabiensis? PLOS ONE 2012, 7:3.

36. Bayoh MN, Mathias D, Odiere M, Mutuku F, Kamau L, Gimnig J, Vulule J، Hawley W, Hamel M, Walker E: Anopheles gambiae: historical population decline associated with regional distribution of insecticide-treated bed nets in western Nyanza Province. Kenya Malar J 2010, 9(1):62.

37. Russell TL, Lwetoijera DW, Maliti D, Chipwaza B, Kihonda J, Charlwood JD, Smith TA, Lengeler C, Mwanyangala MA, Nathan R, et al: Impact of promoting longer-lasting insecticide treatment of bed nets upon malaria transmission in a rural Tanzanian setting with pre-existing high coverage of untreated nets. Malar J 2010, 9:187.

38. Odetoyinbo JAD,G: The Anopheles gambiae species complex and its role in the malaria transmission in the islands of Zanzibar and Pemba, United Republic of Tanzania; 1968.

39. Lines JD, Nassor NS: DDT resistance in Anopheles gambiae declines with mosquito age. Med Vet Entomol 1991, 5(3):261-265.

40. Müller P, Chouaibou M, Pignatelli P, Etang J, Walker ED, Donnelly MJ, Simard F, Ranson HW: Pyrethroid tolerance is associated with elevated expression of antioxidants and agricultural practice in Anopheles arabiensis sampled from an area of cotton fields in Northern Cameroon. Mol Ecol 2008, 17:1 145-1155.

41. Nardini L, Christian RN, Coetzer N, Ranson H, Coetzee M, Koekemoer LL: Detoxification enzymes associated with insecticide resistance in laboratory strains of Anopheles arabiensis of different geographic origin. Parasit \& Vectors 2012, 5:113.

42. Feyereisen R: Insect CYP genes and P450 enzymes. In Insect Molecular Biology and Biochemistry. Edited by Lawrence IG. San Diego: Academic Press; 2012:236-316.

43. Qiu Y, Tittiger C, Wicker-Thomas C, Le Goff G, Young S, Wajnberg E, Fricaux T, Taquet N, Blomquist GJ, Feyereisen R: An insect-specific P450 oxidative decarbonylase for cuticular hydrocarbon biosynthesis. Proc Natl Acad Sci USA 2012, 109(37):14858-14863.

44. Howard RW, Blomquist GJ: Ecological, behavioral, and biochemical aspects of insect hydrocarbons. Annu Rev Entomol 2005, 50:371-393.
45. Marygold SJ, Leyland PC, Seal RL, Goodman JL, Thurmond J, Strelets VB, Wilson RJ, FlyBase C: FlyBase: improvements to the bibliography. Nucleic Acids Res 2013, 41(D1):D751-D757.

46. Baker D, Nolan T, Fischer B, Pinder A, Crisanti A, Russell S: A comprehensive gene expression atlas of sex- and tissue-specificity in the malaria vector, Anopheles gambiae. BMC Genomics 2011, 12(1):296.

47. Liu NN, Pridgeon JW: Metabolic detoxication and the kdr mutation in pyrethroid resistant house flies, Musca domestica (L.). Pestic Biochem Phys 2002, 73(3):157-163.

48. Plapp FW, Hoyer RF: Insecticide resistance in the housefly - decreased rate of absorption as a mechanism of action of a gene that acts as an intensifier of resistance. J Econ Entomol 1968, 61(5):1298.

49. Ahmad M, Denholm I, Bromilow RH: Delayed cuticular penetration and enhanced metabolism of deltamethrin in pyrethroid-resistant strains of Helicoverpa armigera from China and Pakistan. Pest Manag Sci 2006, 62(9):805-810.

50. Valles SM, Dong K, Brenner RJ: Mechanisms responsible for cypermethrin resistance in a strain of German cockroach. Blattella germanica. Pestic Biochem Phys 2000, 66(3):195-205

51. Puinean AM, Foster SP, Oliphant L, Denholm I, Field LM, Millar NS, Williamson MS, Bass C: Amplification of a cytochrome P450 gene is associated with resistance to neonicotinoid insecticides in the aphid Myzus persicae. PLoS Genet 2010, 6(6):e1000999.

52. Zhu F, Gujar H, Gordon JR, Haynes KF, Potter MF, Palli SR: Bed bugs evolved unique adaptive strategy to resist pyrethroid insecticides. Sci Rep 2013, 3:1456.

53. N'Guessan R, Asidi A, Boko P, Odjo A, Akogbeto M, Pigeon O, Rowland M: An experimental hut evaluation of PermaNet (R) 3.0, a deltamethrin-piperonyl butoxide combination net, against pyrethroid-resistant Anopheles gambiae and Culex quinquefasciatus mosquitoes in southern Benin. Trans $R$ Soc Trop Med Hyg 2010, 104(12):758-765.

54. Mawejje HD, Wilding CS, Rippon EJ, Hughes A, Weetman D, Donnelly MJ: Insecticide resistance monitoring of field-collected Anopheles gambiaes. I. populations from Jinja, eastern Uganda, identifies high levels of pyrethroid resistance. Med Vet Entomol, 27:276-283. in press.

55. Ochomo E, Bayoh MN, Brogdon WG, Gimnig JE, Ouma C, Vulule JM, Walker ED: Pyrethroid resistance in Anopheles gambiae s.s. and Anopheles arabiensis in western Kenya: phenotypic, metabolic and target site characterizations of three populations. Med Vet Entomol 2013, 27(2):156-164

56. N'Guessan R, Corbel V, Akogbeto M, Rowland Ml: Reduced efficacy of insecticide-treated nets and indoor residual spraying for malaria control in pyrethroid resistance area, Benin. Emerg Infect Dis 2007, 13(2):199-206.

57. Jones CM, Sanou A, Guelbeogo WM, Sagnon N, Johnson PCD, Ranson H: Aging partially restores the efficacy of malaria vector control in insecticide-resistant populations of Anopheles gambiae s.l. from Burkina Faso. Malar J 2012, 11:24.

58. Killeen GF, Seyoum A, Sikaala C, Zomboko AS, Gimnig JE, Govella NJ, White MT: Eliminating malaria vectors. Parasit Vectors 2013, 6:172.

\section{doi:10.1186/1756-3305-6-343}

Cite this article as: Jones et al:: The dynamics of pyrethroid resistance in Anopheles arabiensis from Zanzibar and an assessment of the underlying genetic basis. Parasites \& Vectors 2013 6:343.

\section{Submit your next manuscript to BioMed Central and take full advantage of:}

- Convenient online submission

- Thorough peer review

- No space constraints or color figure charges

- Immediate publication on acceptance

- Inclusion in PubMed, CAS, Scopus and Google Scholar

- Research which is freely available for redistribution 